\title{
Sleep duration and risk of fatal and nonfatal stroke
}

\author{
A prospective study and meta-analysis \\ OPEN
}

Yue Leng, MPhil

Francesco P. Cappuccio,

MD

Nick W.J. Wainwright, $\mathrm{PhD}$

Paul G. Surtees, PhD

Robert Luben, MSc

Carol Brayne, MD

Kay-Tee Khaw, MD

Correspondence to

Dr. Leng:

yl411@medschl.cam.ac.uk

Editorial, page 1066

Supplemental data at Neurology.org

\section{ABSTRACT}

Objective: To study the association between sleep duration and stroke incidence in a British population and to synthesize our findings with published results through a meta-analysis.

Methods: The prospective study included 9,692 stroke-free participants aged 42-81 years from the European Prospective Investigation into Cancer-Norfolk cohort. Participants reported sleep duration in 1998-2000 and 2002-2004, and all stroke cases were recorded until March 31, 2009. For the meta-analysis, we searched Ovid Medline, EMBASE, and the Cochrane Library for prospective studies published until May 2014, and pooled effect estimates using a weighted random-effect model.

Results: After 9.5 years of follow-up, 346 cases of stroke occurred. Long sleep was significantly associated with an increased risk of stroke (hazard ratio $[\mathrm{HR}]=1.46[95 \%$ confidence interval (Cl) $1.08,1.98])$ after adjustment for all covariates. The association remained robust among those without preexisting diseases and those who reported sleeping well. The association for short sleep was smaller (and not statistically significant) $(H R=1.18[95 \% \mathrm{Cl} 0.91,1.53])$. There was a higher stroke risk among those who reported persistently long sleep or a substantial increase in sleep duration over time, compared to those reporting persistently average sleep. These were compatible with the pooled HRs from an updated meta-analysis, which were 1.15 $(1.07,1.24)$ and $1.45(1.30,1.62)$ for short and long sleep duration, respectively.

Conclusions: This prospective study and meta-analysis identified prolonged sleep as a potentially useful marker of increased future stroke risk in an apparently healthy aging population. Neurology ${ }^{\circledR}$ 2015;84:1072-1079

\section{GLOSSARY}

BMI = body mass index; $\mathbf{C l}=$ confidence interval; $\mathbf{C V D}=$ cardiovascular disease; $\mathbf{D B P}=$ diastolic blood pressure; $\mathbf{H R}=$ hazard ratio; ICD-9 = International Classification of Diseases-9; ICD-10 = International Classification of Diseases-10; MDD = major depressive disorder; $\mathbf{M I}=$ myocardial infarction; $\mathbf{S B P}=$ systolic blood pressure .

Sleep is increasingly suggested as a predictor of cardiovascular events, ${ }^{1,2}$ and stroke is an outcome of particular interest. One meta-analysis in $2009^{2}$ included 4 studies on sleep and stroke ${ }^{3-6}$ and concluded a U-shaped relationship, with both short and long sleep being associated with an increased stroke risk.

Increasing numbers of prospective studies have examined this association in the past 5 years. ${ }^{7-10}$ These studies have examined various types of populations with different follow-up durations, with inconsistent results. While several earlier studies observed strong effects for long sleep and suggested a J-shaped relationship, ${ }^{3,4,11}$ the most recent study found a U-shaped association between sleep duration and risk of stroke mortality in a large sample of Chinese adults. ${ }^{8}$ It is unclear whether this association is applicable to nonfatal stroke, and if this could be modified by sleep quality. Meanwhile, evidence is lacking from the British population, and no study has examined change in sleep duration over time and subsequent stroke risk. Understanding this relationship is potentially important for the early detection of stroke, especially in older populations. Therefore, we aimed to update the meta-analysis, and to study the effects of

From the Department of Public Health and Primary Care (Y.L., N.W.J.W., P.G.S., R.L., C.B., K.-T.K.), University of Cambridge; and the Division of Mental Health \& Wellbeing (F.P.C.), University of Warwick, Coventry, UK.

Go to Neurology.org for full disclosures. Funding information and disclosures deemed relevant by the authors, if any, are provided at the end of the article. The Article Processing Charge was paid by CRUK and RCUK.

This is an open access article distributed under the Creative Commons Attribution License, which permits unrestricted use, distribution, and reproduction in any medium, provided the original work is properly cited. 
sleep duration and change in sleep duration on stroke incidence in a middle- to older-aged British population. We evaluated both fatal and nonfatal stroke and explored whether the associations varied by follow-up length, stroke subtypes, and sleep quality.

METHODS Study population. The study population was drawn from the European Prospective Investigation of CancerNorfolk cohort study. Details about study design have been described previously. ${ }^{12}$ Briefly, we recruited 25,639 men and women aged 40-79 years using general practice age-sex registers from Norfolk, UK, during 1993-1997, and followed them up for health outcomes. As part of the follow-up, participants were sent questionnaires for completion.

Standard protocol approvals, registrations, and patient consents. The Norwich District Ethics Committee approved the study and all participants gave signed informed consent.

Measures of sleep. During 1998-2000, 16,643 people answered the following question: "On average, how many hours do you sleep in a 24-hour period?" with 6 response options: $<4$, $4-6,6-8,8-10,10-12$, and $>12$. This question was repeated during 2002-2004.

In addition, participants were asked "Do you generally sleep well?" with response alternatives "yes" and "no."

Ascertainment of stroke cases. At baseline, we excluded participants with self-reported history of doctor-diagnosed stroke or those whose date of stroke onset was before the date of sleep report. All stroke cases to March 31, 2009, were taken as the first occurrence of either hospital admission or death due to stroke. We defined nonfatal stroke as hospital admission due to stroke that did not lead to death (in the same month), and recorded information through linkage with the National Health Services district database. We obtained information on fatal stroke through linkage with the UK Office of National Statistics. Stroke cases were classified according to ICD-9 as codes 430-438 (hemorrhagic stroke 430-432; cerebral infarction 433-435; stroke unspecified or other 436-438) or according to $I C D-10$ as codes I60-I69 (hemorrhagic stroke I60-I62; ischemic stroke I63, I65, and I66; stroke unspecified or other I64 and I67-I69).

Covariates. We chose all covariates a priori based on literature and relevance to sleep and stroke. Those reported from questionnaires included age, sex, social class (professionals, managerial, and technical occupations, skilled workers subdivided into nonmanual and manual, partly skilled workers, and unskilled manual workers), education (no qualifications, educated to age 16, educated to age 18, and educated to degree level), marital status (single, married, widowed, separated, and divorced), smoking (current, former, and nonsmokers), alcohol intake (units of alcohol per week), family history of stroke, hypnotic drug use, physical activity (inactive, moderately inactive, moderately active, active), major depressive disorder (MDD) in the previous year, preexisting myocardial infarction (MI) and diabetes, and use of antihypertension drugs.

Other objectively measured confounders included body mass index (BMI; weight in kilograms divided by height in meters squared); systolic blood pressure (SBP) and diastolic blood pressure (DBP), both in $\mathrm{mm} \mathrm{Hg}$, based on the mean of 2 readings taken by trained nurses; and serum cholesterol level estimated from nonfasting blood samples taken by venepuncture, using colorimetry (RA 1000, Bayer Diagnostics, Basingstoke, UK).
Statistical analysis. We defined the response categories for sleep duration as short ( $<6$ hours), average ( $6-8$ hours), and long $(>8$ hours) due to the low frequency of extreme sleep durations. First, we compared baseline characteristics of the participants by sleep duration using $\chi^{2}$ test. Cox proportional hazard models were fitted to obtain hazard ratios (HR), with average sleep being the reference group. We constructed models with progressive adjustment of the covariates to show the associations explained by the covariates and performed the analysis in those with complete data on all covariates (A) adjusted for age and sex; (B) further adjusted for social class, education, marital status, smoking, alcohol intake, hypnotic drug use, and family history of stroke; and (C) further adjusted for BMI, physical activity, MDD, SBP, DBP, preexisting $\mathrm{MI}$ and diabetes, serum cholesterol level, and hypertension drug use. We repeated these analyses for fatal and nonfatal stroke, and presented the results by sex.

Change in sleep duration from 1998-2000 to 2002-2004 was modeled through combinations of the 3 duration categories during each time period, giving 9 subcategories. The association between change in sleep duration and overall incidence risk of stroke was examined using model C, with "constantly average" being the reference group, and was conducted in the whole sample to retain power. Finally, we performed subgroup analysis according to follow-up length, sleep quality, preexisting diseases, stroke subtypes, and other potential effect modifiers using model B. Analyses were implemented in STATA, version 12.0 (StataCorp LP, College Station, TX).

Meta-analysis of prospective studies on the association between sleep duration and stroke incidence. We conducted an updated systematic review and meta-analysis using methods described in detail elsewhere. ${ }^{2}$ We searched longitudinal population studies (published up to May 2014) reporting the association between sleep duration and fatal and nonfatal stroke (appendix e-1 on the Neurology ${ }^{\circledR}$ Web site at Neurology.org), with the following restrictions: original article, prospective cohort design, and adult population. Studies with no complete information presented for stroke events were contacted, and were excluded if no additional estimates could be obtained. Data were extracted independently by 2 investigators (Y.L. and F.P.C.). Short sleep was defined as $\leq 5-6$ hours and long sleep as $\geq 8-9$ hours. When multiple multivariate models were fitted, we extracted the estimates that were least likely to have been confounded (models with most covariates). Effect estimates were pooled using a weighted random-effect model. We tested for heterogeneity among studies, ${ }^{13}$ publication bias by funnel plot asymmetry and Egger test, ${ }^{14}$ and carried out sensitivity analyses. ${ }^{2}$ All analyses were performed using Review Manager software (v5) (Copenhagen, 2011). We evaluated the quality of studies, ${ }^{15}$ and the study adheres to the PRISMA Statement guidelines for nonrandomized studies. ${ }^{16}$

RESULTS After excluding participants with selfreported preexisting stroke $(\mathrm{n}=438)$ and those whose date of stroke onset was before the date of sleep report $(n=623)$, the final study sample included 9,692 participants who had complete data on all covariates.

At baseline, the participants were aged from 42 to 81 years (mean 61.6). A total of 6,684 (69\%) of the participants reported sleeping for 6-8 hours per day, while $10 \%$ reported sleeping for $>8$ hours. Table 1 shows baseline characteristics by sleep duration. 


\begin{tabular}{|c|c|c|c|c|}
\hline \multirow[t]{2}{*}{ Cancer-Norfolk study, } & \multirow[b]{2}{*}{$\begin{array}{l}\text { Total, } \\
\text { n (\%) }\end{array}$} & \multirow[b]{2}{*}{$<6$ h (n = 2,022), n (\%) } & \multirow[b]{2}{*}{$6-8 \mathrm{~h}(\mathrm{n}=6,684), \mathrm{n}(\%)$} & \multirow[b]{2}{*}{$>8 \mathrm{~h}(\mathrm{n}=986), \mathrm{n}(\%)$} \\
\hline & & & & \\
\hline \multicolumn{5}{|l|}{ Age, y } \\
\hline $42-52$ & 1,819 & $333(16.5)^{\mathrm{a}}$ & 1,324 (19.8) & $162(16.4)$ \\
\hline $52-62$ & 3,384 & 702 (34.7) & $2,374(35.5)$ & 308 (31.2) \\
\hline $62-72$ & 3,140 & $634(31.4)$ & 2,158 (32.3) & 348 (35.3) \\
\hline $72-82$ & 1,349 & 353 (17.5) & $828(12.4)$ & $168(17.0)$ \\
\hline Male sex & 4,444 & $807(39.9)^{a}$ & $3,204(47.9)$ & $433(43.9)$ \\
\hline Nonmanual social class & 6,359 & $1,267(62.7)^{b}$ & 4,448 (66.5) & 644 (65.3) \\
\hline A-level and higher education & 5,733 & $1,086(53.7)^{a}$ & $4,060(60.7)$ & 587 (59.5) \\
\hline Married & 8,012 & $1,559(77.1)^{a}$ & $5,617(84.0)$ & $836(84.8)$ \\
\hline Current or former smoker & 4,983 & $1,047(51.8)$ & $3,423(51.2)$ & $513(52.0)$ \\
\hline Alcohol intake $\geq 8$ units/wk ${ }^{c}$ & 4,655 & $924(45.7)$ & $3,248(48.6)$ & $483(49.0)$ \\
\hline Hypnotics use & 145 & $80(4.0)^{a}$ & $59(0.9)$ & $6(0.6)$ \\
\hline Family history of stroke & 7,291 & 501 (24.8) & $1,655(24.8)$ & $245(24.8)$ \\
\hline $\mathrm{BMI}>26.5^{\mathrm{C}}$ & 4,757 & $1,028(50.8)$ & $3,228(48.3)$ & $501(50.8)$ \\
\hline \multicolumn{5}{|l|}{ Physical activity } \\
\hline Inactive & 2,383 & $570(28.2)^{a}$ & $1,548(23.2)$ & 265 (26.9) \\
\hline Moderately inactive & 2,912 & 578 (28.6) & 2,048 (30.6) & $286(29.0)$ \\
\hline Moderately active & 2,429 & 484 (23.9) & $1,715(25.7)$ & $230(23.3)$ \\
\hline Active & 1,968 & 390 (19.3) & $1,373(20.5)$ & $205(20.8)$ \\
\hline Major depressive disorder & 441 & $138(6.8)^{\mathrm{a}}$ & $248(3.7)$ & $55(5.6)$ \\
\hline Hypertension drug use & 2,039 & $493(24.4)^{\mathrm{a}}$ & $1,323(19.8)$ & $223(22.6)$ \\
\hline Systolic blood pressure $\geq 137 \mathrm{~mm} \mathrm{Hg}^{\mathrm{c}}$ & 4,842 & $1,019(50.4)$ & $3,301(49.4)$ & $522(52.9)$ \\
\hline Cholesterol level $\geq 5.9 \mathrm{mmol} / \mathrm{L}^{\mathrm{c}}$ & 4,650 & 974 (48.2) & $3,192(47.8)$ & $484(49.1)$ \\
\hline Self-reported diabetes & 254 & $49(2.4)$ & $177(2.6)$ & $28(2.8)$ \\
\hline Self-reported heart attack & 293 & $70(3.5)$ & $185(2.8)$ & 38 (3.9) \\
\hline
\end{tabular}

Participants with $<6$ hours or $>8$ hours of sleep were older, more likely to be women, less active, to have MDD, and to be taking antihypertensive drugs. No significant association was found between sleep duration and BMI, SBP, or preexisting diabetes or MI.

A total of 346 participants had at least one incident fatal or nonfatal stroke during a mean of 9.5 years of follow-up. There were 67 fatal stroke and 300 hospital admissions, with 21 participants being admitted to hospital before subsequent death. Univariate analysis suggested that those who reported $<6$ hours and $>8$ hours of sleep had $32 \%$ and $71 \%$ increased risk of having a stroke incident, respectively. Table 2 summarizes the adjusted HRs associated with short and long sleep. After adjustment for age and sex, short and long sleep were associated with $19 \%$ and $45 \%$ increase in the risk of stroke, respectively. These estimates were hardly changed after further adjustment for potential confounders. The association was stronger for women, although a formal test for sex difference was not statistically significant $(p=0.24)$. When we examined stroke outcomes separately, the association was more pronounced for fatal stroke (table e-1).

Table 3 shows the association between change in sleep duration and stroke risk. The risk doubled for those reporting persistently long sleep, compared to those with persistently average sleep duration. This risk was even greater for those whose reported sleep increased from short to long over the 4 years $(\mathrm{HR}=$ 3.75 [95\% confidence interval (CI), 1.17, 12.05]). Finally, subgroup analysis (table e-2) suggested that the association remained among those without preexisting diseases, did not attenuate by increasing 


\begin{tabular}{|c|c|c|c|c|c|c|c|}
\hline \multirow[t]{2}{*}{ Table 2} & \multirow{2}{*}{ No. of patients } & rvals) o & $p$ duration $\mathrm{fc}$ & \multirow{2}{*}{$6-8 \mathrm{~h}$, referent } & \multirow{2}{*}{\multicolumn{2}{|c|}{$>8 \mathrm{~h}$}} & \multirow{2}{*}{ Overall $p^{a}$} \\
\hline & & \multicolumn{2}{|l|}{$<6 \mathrm{~h}$} & & & & \\
\hline All $(n=9,692)$ & 346 & & & & & & \\
\hline Model $1^{b}$ & & 1.19 & $(0.92,1.53)$ & 1.00 & 1.45 & $(1.07,1.97)$ & 0.05 \\
\hline Model $3^{d}$ & & 1.18 & $(0.91,1.53)$ & 1.00 & 1.46 & $(1.08,1.98)$ & 0.05 \\
\hline Men $(n=4,444)$ & 198 & & & & & & \\
\hline Model $1^{b}$ & & 1.14 & $(0.80,1.63)$ & 1.00 & 1.24 & $(0.82,1.87)$ & 0.52 \\
\hline Model $2^{c}$ & & 1.07 & $(0.74,1.54)$ & 1.00 & 1.24 & $(0.82,1.87)$ & 0.59 \\
\hline Model $2^{c}$ & & 1.26 & $(0.86,1.84)$ & 1.00 & 1.78 & $(1.12,2.82)$ & 0.05 \\
\hline Model $3^{d}$ & & 1.25 & $(0.86,1.83)$ & 1.00 & 1.80 & $(1.13,2.85)$ & 0.05 \\
\hline
\end{tabular}

Abbreviations: $\mathrm{Cl}=$ confidence interval; $\mathrm{HR}=$ hazard ratio.

a Tested by likelihood ratio test.

${ }^{\mathrm{b}}$ Adjusted for age and sex.

${ }^{\mathrm{c}}$ Adjusted for age, sex, social class, education, marital status, smoking, alcohol intake, hypnotic drug use, and family history of stroke.

${ }^{\mathrm{d}}$ Adjusted for age, sex, social class, education, marital status, smoking, alcohol intake, hypnotic drug use, family history of stroke, body mass index, physical activity, depression, hypnotic drug use, systolic blood pressure, diastolic blood pressure, preexisting diabetes and myocardial infarction, cholesterol level, and hypertension drug use.

length of follow-up, and was more pronounced for those who reported sleeping well $(p$ for interaction $=0.01)$. The association for short sleep was strong among younger people $(\mathrm{HR}=1.87[0.97$, $3.60]$ ) and the association for long sleep was only significant among those aged 63 years and older $(\mathrm{HR}=1.50[1.09,2.05])(p$ for interaction $=$ $0.98)$. The association was stronger between short sleep and ischemic stroke and between long sleep and hemorrhagic stroke.

Systematic review and meta-analysis. Eleven studies $^{3-8,10,11,17-19}$ identified from the search along with the current study were included (table e-3) in the meta-analysis. Six studies reported outcomes separately for men and women, and were entered as separate

Table 3 Change in sleep duration over 2 measurements and stroke incidence, 1998-2009

\begin{tabular}{|c|c|c|c|c|}
\hline \multicolumn{2}{|c|}{ Sleep duration ${ }^{a}$} & \multirow[b]{2}{*}{ No. of patients } & \multicolumn{2}{|c|}{ Stroke incidence risk } \\
\hline $1998-2000$ & $2002-2004$ & & HR & $95 \% \mathrm{Cl}$ \\
\hline Average & Average & 6,646 & 1.00 & Referent \\
\hline Short & Average & 905 & 1.30 & $(0.74,2.18)$ \\
\hline Long & Average & 608 & 1.33 & $(0.74,2.38)$ \\
\hline Short & Short & 1,759 & 1.11 & $(0.71,1.73)$ \\
\hline Average & Short & 1,161 & 1.12 & $(0.66,1.88)$ \\
\hline Long & Short & 45 & 1.36 & $(0.18,9.91)$ \\
\hline Average & Long & 825 & 1.53 & $(0.96,2.44)$ \\
\hline Long & Long & 648 & $2.01^{\mathrm{b}}$ & $(1.26,3.23)$ \\
\hline Short & Long & 52 & $3.75^{c}$ & $(1.17,12.05)$ \\
\hline
\end{tabular}

Abbreviations: $\mathrm{Cl}=$ confidence interval; $\mathrm{HR}=$ hazard ratio.

a Short: $<6$ hours; average: $6-8$ hours; long: $>8$ hours.

${ }^{b} \mathrm{p}<0.01$.

${ }^{c} p<0.05$ adjusted for age, sex, social class, education, marital status, smoking, alcohol intake, hypnotic drug use, family history of stroke, body mass index, physical activity, depression, hypnotic drug use, systolic blood pressure, diastolic blood pressure, preexisting diabetes and myocardial infarction, cholesterol level, and hypertension drug use. 
cohorts. The final analysis included 559,252 participants from 7 countries. All studies measured sleep duration by questionnaire, and 6 only reported fatal stroke events. Over a follow-up of 7.5-35 years, a total of 11,695 stroke events were reported. The figure shows the pooled effects for short (A) and long (B) sleep, respectively. The addition of the current study did not alter the overall estimates of effect for both short and long sleep. For short sleep, the pooled relative risk (RR) was 1.15 (95\% CI, 1.07, 1.24; $p=0.0002$ ), with no evidence of heterogeneity. For long sleep, the pooled RR was $1.45(1.30,1.62)$, with significant between-study heterogeneity $\left(I^{2}=54 \%\right.$; $p=0.003)$. After repeating the meta-analysis excluding the study by Westerlund et al., ${ }^{7}$ the heterogeneity disappeared (RR, 1.53; 95\% CI, 1.42, $\left.1.65 ; p<0.00001 ; P^{2}=0 \%\right)$.

DISCUSSION In this middle-to older-aged British population, we observed a J-shaped relationship between daily sleep duration and 9.5-year stroke risk. Those with short sleep had an 18\% increased stroke risk (not statistically significant), while long sleep was associated with a $46 \%$ increase in stroke risk after adjustment for conventional cardiovascular disease (CVD) risk factors and comorbidities. Those who reported persistently long sleep and those who reported substantially increased sleep had at least double the stroke risk compared to those with persistently average sleep duration. Our findings are compatible with an updated meta-analysis, which suggested a pooled RR of $1.15(1.07,1.24)$ and 1.45 $(1.30,1.62)$ for short and long sleep, respectively.

This study benefits from the prospective design, particularly the ability to examine the longitudinal change in sleep duration. Both fatal and nonfatal stroke events were examined, and sex-specific estimates were provided. The study also explored whether the association differed by comorbidities, general sleep quality, and stroke subtypes, which helps to provide more insights into potential mechanisms. The meta-analysis including over 8,000 stroke cases, substantially greater than that included in previous work, ${ }^{2}$ provides external validity to our findings. There are several limitations. First, this study included 9,692 stroke-free participants who were younger and had higher social class and educational level compared to the baseline population, but the external validity is supported by the agreement with the meta-analysis. As with previous studies, sleep duration was reported via a single question, which might reflect perception of sleep rather than biological sleep. It should be noted that one's perception of sleep could be influenced by poor cognitive function or physical health. ${ }^{20,21}$ This is potentially problematic for older adults and for those with preclinical minor stroke, whose perception of sleep might be impaired due to cognitive factors. However, examination of change in sleep duration was in line with results on a single measure of sleep at baseline. From a practical standpoint, evaluation of sleep durations using selfreported data are more feasible in primary care settings. Although a range of potential confounders were included in the analysis, we could not rule out the possibility of residual confounding. For example, the effects of unmeasured health or sleep problems (e.g., obstructive sleep apnea or snoring) cannot be overlooked, particularly on the association for long sleep. We evaluated general sleep quality by asking if one generally sleeps well. This is a relatively crude measure, and we were unable to differentiate between short sleep due to poor sleep quality or time constraints and natural short sleepers. However, our observation on the interaction between perception of sleep duration and general sleep quality provides interesting insights to the problem and stresses the need for further studies. Finally, failure to reach statistical significance in the short sleep group may reflect low statistical power due to the small number of events. In order to retain power, we have defined short sleepers as those who reported sleeping less than 6 hours, and might have failed to detect the association for extremely short sleepers as reported by previous studies. ${ }^{22,23}$ While the association for short sleep could have been underestimated, the point estimate was compatible with that of the meta-analysis.

In accordance with previous studies,,$^{3,4,6,8,11}$ we found a robust association between long sleep and increased stroke risk. The Women's Health Initiative study has shown similar results on the risk of ischemic stroke among postmenopausal women. ${ }^{4}$ We extended the analysis to all stroke events in both sexes, and suggested a stronger association among women. The Singapore Chinese Health Study ${ }^{8}$ found both short and long sleep to be associated with mortality from ischemic or unspecified stroke, while our study suggested an association between short sleep and risk of ischemic stroke, and between long sleep and hemorrhagic stroke. It is unclear why different sleep lengths might be associated with different stroke subtypes. Notably, the numbers in each subtypes of stroke were relatively small, and larger studies are required to replicate our findings and help to inform mechanisms.

A few studies on middle-aged participants have reported either no association between sleep duration and stroke risk ${ }^{7,17}$ or association only for short sleep. ${ }^{10}$ A recent study suggested an increased risk of stroke associated with insomnia, particularly in young adults. ${ }^{9}$ Consistent with these studies, we found the association for short sleep stronger among younger participants, but for long sleep more pronounced among the older ones, although test for interaction 
A

\section{Study or subgroup}

Present (men)

Present (women)

Ref. 10

Ref. 11 (men)

Ref. 11 (women)

Ref. 17 (men)

Ref. 18

Ref. 19 (men)

Ref. 19 (women)

Ref. 3

Ref. 4

Ref. 5 (men)

Ref. 5 (women)

Ref. 6 (men)

Ref. 6 (women)

Ref. 7

Ref. 8 (men)

Ref. 8 (women)
Log

\section{(Risk}

$\begin{array}{rrr}0.077 & 0.186 & 198 \\ 0.2231 & 0.1908 & 148 \\ 0.7227 & 0.2843 & 169 \\ 0.0198 & 0.1637 & 627 \\ 0.1484 & 0.1409 & 632 \\ 0.6098 & 1.061 & 30 \\ 0.0488 & 0.1139 & 1165 \\ 0.0677 & 0.1679 & 1057 \\ 0.1398 & 0.1424 & 1125 \\ 0 & 0.1893 & 285 \\ 0.131 & 0.0824 & 1166 \\ 0.2624 & 1.0088 & 34 \\ 1.16 & 0.6022 & 29 \\ 0.4383 & 0.3311 & 1038 \\ 0.0677 & 0.2952 & 926 \\ 0.0488 & 0.1387 & 1685 \\ 0.1222 & 0.1393 & 693 \\ 0.3148 & 0.1214 & 688\end{array}$

Participants Total Weight IV, random, 95\%

$4444 \quad 4.2 \% \quad 1.08[0.75,1.56]$

$5248 \quad 4.0 \% \quad 1.25[0.86,1.82]$

$23620 \quad 1.8 \%$

$61936 \quad 5.4 \%$

$73749 \quad 7.3 \%$

$2282 \quad 0.1 \%$

$49256 \quad 11.2 \%$

$11373 \quad 5.1 \%$

$11917 \quad 7.1 \%$

$7844 \quad 4.0 \%$

$93175 \quad 21.3 \%$

$4419 \quad 0.1 \%$

$6906 \quad 0.4 \%$

$41489 \quad 1.3 \%$

$57145 \quad 1.7 \%$

$41192 \quad 7.5 \%$

$27954 \quad 7.5 \%$

$35303 \quad 9.8 \%$
$2.06[1.18,3.60]$

$1.02[0.74,1.41]$

$1.16[0.88,1.53]$

$1.84[0.23,14.72]$

$1.05[0.84,1.31]$

$1.07[0.77,1.49]$

$1.15[0.87,1.52]$

$1.00[0.69,1.45]$

$1.14[0.97,1.34]$

$1.30[0.18,9.39]$

$3.19[0.98,10.38]$

$1.55[0.81,2.97]$

$1.07[0.60,1.91]$

$1.05[0.80,1.38]$

$1.13[0.86,1.48]$

$1.37[1.08,1.74]$

Total $(95 \% \mathrm{Cl})$

$11695 \quad 559252 \quad 100.0 \%$

Heterogeneity: Tau $^{2}=0.00 ; \mathrm{Chi}^{2}=12.91, \mathrm{df}=17(\mathrm{P}=0.74) ; \mathrm{I}^{2}=0 \%$

Test for overall effect: $Z=3.69(P=0.0002)$

$1.15[1.07,1.24]$

Risk ratio
$\mathrm{Cl} \quad \mathrm{IV}$, random, $95 \% \mathrm{CI}$

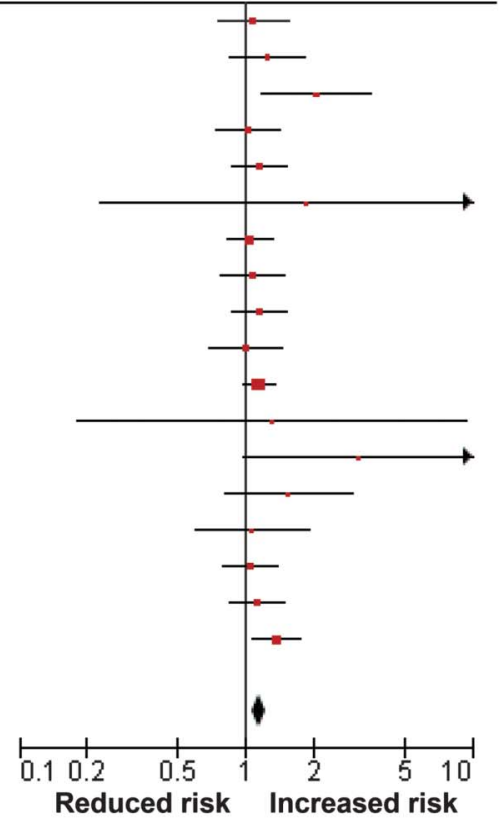

\begin{tabular}{|c|c|c|c|c|c|c|c|c|}
\hline & Log & Eve & & Partici & ipants & Risk ratio & Risk & ratio \\
\hline Study or subgroup & (Risk ratio) & SE & Total & Total & Weight & IV, random, $95 \% \mathrm{CI}$ & IV, rando & $\mathrm{m}, 95 \% \mathrm{Cl}$ \\
\hline Present (men) & 0.1906 & 0.2069 & 198 & 4444 & $4.6 \%$ & $1.21[0.81,1.82]$ & & - \\
\hline Present (women) & 0.5878 & 0.2375 & 148 & 5248 & $3.9 \%$ & $1.80[1.13,2.87]$ & & $\longrightarrow$ \\
\hline Ref. 10 & 0.5008 & 0.2555 & 169 & 23620 & $3.5 \%$ & $1.65[1.00,2.72]$ & & \\
\hline Ref. 11 (men) & 0.3001 & 0.138 & 627 & 61936 & $7.0 \%$ & $1.35[1.03,1.77]$ & & - \\
\hline Ref. 11 (women) & 0.3293 & 0.1383 & 632 & 73749 & $6.9 \%$ & $1.39[1.06,1.82]$ & & 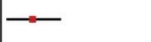 \\
\hline Ref. 17 (men) & 0.8109 & 0.4619 & 30 & 2282 & $1.4 \%$ & $2.25[0.91,5.56]$ & & \\
\hline Ref 18 & 0.4121 & 0.1005 & 1165 & 49256 & $8.6 \%$ & $1.51[1.24,1.84]$ & & $=-$ \\
\hline Ref 19 (men) & 0.2311 & 0.2192 & 1057 & 11373 & $4.3 \%$ & $1.26[0.82,1.94]$ & & - \\
\hline Ref. 19 (women) & 0.3365 & 0.1717 & 1125 & 11917 & $5.7 \%$ & $1.40[1.00,1.96]$ & & - \\
\hline Ref. 3 & 0.4121 & 0.1524 & 285 & 7844 & $6.4 \%$ & $1.51[1.12,2.04]$ & & $\rightarrow$ \\
\hline Ref. 4 & 0.5306 & 0.1214 & 1166 & 93175 & $7.7 \%$ & $1.70[1.34,2.16]$ & & $\rightarrow$ \\
\hline Ref. 5 (men) & 0.1823 & 0.457 & 34 & 4419 & $1.4 \%$ & $1.20[0.49,2.94]$ & & \\
\hline Ref. 5 (women) & 0.9203 & 0.5898 & 29 & 6906 & $0.9 \%$ & $2.51[0.79,7.97]$ & & \\
\hline Ref. 6 (men) & 0.5128 & 0.12 & 1038 & 41489 & $7.7 \%$ & $1.67[1.32,2.11]$ & & $\rightarrow$ \\
\hline Ref. 6 (women) & 0.5188 & 0.1387 & 926 & 57145 & $6.9 \%$ & $1.68[1.28,2.20]$ & & $\rightarrow$ \\
\hline Ref. 7 & -0.1393 & 0.0966 & 1685 & 41192 & $8.8 \%$ & $0.87[0.72,1.05]$ & - & \\
\hline Ref. 8 (men) & 0.3988 & 0.1277 & 693 & 27954 & $7.4 \%$ & $1.49[1.16,1.91]$ & & $\rightarrow$ \\
\hline Ref. 8 (women) & 0.4824 & 0.1364 & 688 & 35303 & $7.0 \%$ & $1.62[1.24,2.12]$ & & $\rightarrow$ \\
\hline Total $(95 \% \mathrm{Cl})$ & & & 11695 & 559252 & $100.0 \%$ & $1.45[1.30,1.62]$ & & $\bullet$ \\
\hline $\begin{array}{l}\text { Heterogeneity: } \operatorname{Tau}^{2}=0 \\
\text { Test for overall effect: } Z\end{array}$ & $\begin{array}{l}3 ; \mathrm{Chi}^{2}=37.29 \\
6.50(\mathrm{P}=0.00\end{array}$ & $\begin{array}{l}9, d f=17 \\
0001)\end{array}$ & $(P=0.00$ & $=54 \%$ & & & $\begin{array}{cc}2 & 0.5 \\
\text { duced risk }\end{array}$ & $\begin{array}{c}1 \\
2 \\
\text { Increa }\end{array}$ \\
\hline
\end{tabular}

Association between short (A) and long (B) sleep duration and risk of stroke. Results are presented as pooled relative risk and $95 \%$ confidence interval (CI).

was not statistically significant. Short and long sleep might have different implications in different age groups, and the interaction by age needs to be tested by larger studies in the future. Although it is possible for older people to sleep more due to less work and social demands, we have previously suggested decreased self-reported sleep duration for older participants despite long time spent in bed in this cohort. ${ }^{24}$ Therefore, it is worth noting excessive sleep as an early sign of increased stroke risk, particularly among older people. This study suggests that those who reported persistently long sleep or substantially increased sleep had a much higher stroke risk. This again points to the importance of detecting prolonged sleep among the aging population. While there are no other studies with which to directly compare our 
findings, stability of sleep as a trait is important $\mathrm{t}^{25}$ and future studies are needed to explore this matter.

The underlying mechanisms are not fully understood. Sleep deprivation has been linked to disrupted metabolism and increased cortisol secretion, sympathetic nervous activity, and low-grade inflammation, which might lead to elevated blood pressure, interrupted blood flow, and increased stroke risk. ${ }^{26-28}$ The present prospective study and the updated meta-analysis, however, have both suggested a stronger association for long sleep duration, independent of conventional CVD risk factors. This raises the question of whether long sleep could be a cause, consequence, or early marker of ill health. ${ }^{29}$ One important biological pathway is through inflammation, as long sleep has been associated with an increased level of inflammatory biomarkers. ${ }^{30,31}$ Interestingly, a number of studies have associated long sleep with cardiovascular conditions including carotid artery atherosclerosis, atrial fibrillation, white matter hyperintensity volume, and left ventricular mass, which might have predisposed one to the risk of stroke. ${ }^{32-37}$ These further supported the assumption of long sleep being a risk factor for stroke. Meanwhile, some studies suggested an association for long sleep and stroke only among those with limited physical function ${ }^{18}$ or with a history of hypertension. ${ }^{8}$ The First National Health and Nutrition Examination Survey (NHANES I) concluded that long sleep might represent underlying sleep-specific disease. ${ }^{3}$ Notably, our study remained robust among those without comorbidities or who reported sleeping well, and did not attenuate with increasing length of follow-up, which makes reverse causality an unlikely explanation. Long sleep might be an early sign of system dysregulation and future stroke risk in an apparently healthy, aging population. Further targeted research is needed to examine the additional contribution of habitual sleep duration to existing risk prediction models of stroke. The mechanisms for the health risk associated with long sleep duration should be investigated using experimental designs. ${ }^{38}$

This prospective study and meta-analysis suggested a significant increase in stroke risk among long sleepers and a modest increase among short sleepers. Persistently long sleep or marked increase in sleep duration were associated with subsequent risk of stroke. The underlying mechanism needs further investigation. Prolonged sleep might be a useful marker of increased stroke risk in older people, and should be tested further for its utility in clinical practice.

\section{AUTHOR CONTRIBUTIONS}

The work presented here was carried out in collaboration among all authors. Drafting/revising the manuscript for content, including medical writing for content: Y.L., F.P.C., N.W.J.W., P.G.S., R.L., C.B., K.-T.K. Study concept or design: Y.L., F.P.C., N.W.J.W., P.G.S., C.B., K.-T.K. Analysis or interpretation of data: Y.L., F.P.C., N.W.J.W., P.G.S., C.B., K.-T.K. Acquisition of data: R.L. Statistical analysis: Y.L., F.P.C. Study supervision or coordination: K.-T.K. Obtaining funding: K.-T.K.

\section{STUDY FUNDING}

The design and conduct of the EPIC-Norfolk study was supported by program grants from the Medical Research Council of the United Kingdom (grants G9502233 and G1000143) and Cancer Research UK (grants SP2024/0204 and C864/A14136). The Article Processing Charge was paid by CRUK and RCUK.

\section{DISCLOSURE}

Y. Leng is supported by Cambridge Commonwealth, European \& International Trusts. F. Cappuccio leads the Sleep Health \& Society Programme at the University of Warwick supported, in part, by the University of Warwick RDF and IAS. It has received funding by the NHS National Workforce Projects and the Economic \& Social Research Council (ES/K002910/1). N. Wainwright, P. Surtees, R. Luben, C. Brayne, and K. Khaw report no disclosures. Go to Neurology.org for full disclosures.

Received July 25, 2014. Accepted in final form October 27, 2014.

\section{REFERENCES}

1. Knutson K. Sleep duration and cardiometabolic risk: a review of the epidemiologic evidence. Best Pract Res Clin Endocrinol Metab 2010;24:731-743.

2. Cappuccio FP, Cooper D, D'Elia L, Strazzullo P, Miller MA. Sleep duration predicts cardiovascular outcomes: a systematic review and meta-analysis of prospective studies. Eur Heart J 2011;32:1484-1492.

3. Qureshi AI, Giles WH, Croft JB, Bliwise DL. Habitual sleep patterns and risk for stroke and coronary heart disease: a 10-year follow-up from NHANES I. Neurology 1997;48:904-911.

4. Chen JC, Brunner RL, Ren H, et al. Sleep duration and risk of ischemic stroke in postmenopausal women. Stroke 2008;39:3185-3192.

5. Amagai Y, Ishikawa $S$, Gotoh T, et al. Sleep duration and mortality in Japan: the Jichi Medical School Cohort Study. J Epidemiol 2004;14:124-128.

6. Ikehara $\mathrm{S}$, Iso H, Date $\mathrm{C}$, et al. Association of sleep duration with mortality from cardiovascular disease and other causes for Japanese men and women: the JACC study. Sleep 2009;32:295-301.

7. Westerlund A, Bellocco R, Sundström J, Adami HO, Åkerstedt T, Trolle Lagerros Y. Sleep characteristics and cardiovascular events in a large Swedish cohort. Eur J Epidemiol 2013;28:463-473.

8. Pan A, De Silva DA, Yuan JM, Koh WP. Sleep duration and risk of stroke mortality among Chinese adults: Singapore Chinese Health Study. Stroke 2014;45: 1620-1625.

9. Wu MP, Lin HJ, Weng SF, Ho CH, Wang JJ, Hsu YW. Insomnia subtypes and the subsequent risks of stroke: report from a nationally representative cohort. Stroke 2014;45:1349-1354.

10. von Ruesten A, Weikert C, Fietze I, Boeing H. Association of sleep duration with chronic diseases in the European Prospective Investigation into Cancer and Nutrition (EPIC)-Potsdam study. PLoS One 2012;7:e30972.

11. Kim Y, Wilkens LR, Schembre SM, Henderson BE, Kolonel LN, Goodman MT. Insufficient and excessive amounts of sleep increase the risk of premature death from 
cardiovascular and other diseases: the Multiethnic Cohort Study. Prev Med 2013;57:377-385.

12. Day N, Oakes SA, Luben R, et al. EPIC-Norfolk: study design and characteristics of the cohort. European Prospective Investigation of Cancer. Br J Cancer 1999;80(suppl 1): 95-103.

13. Higgins JP, Thompson SG, Deeks JJ, Altman DG. Measuring inconsistency in meta-analyses. BMJ 2003;327: 557-560.

14. Egger M, Davey Smith G, Schneider M, Minder C. Bias in meta-analysis detected by a simple, graphical test. BMJ 1997;315:629-634.

15. Downs SH, Black N. The feasibility of creating a checklist for the assessment of the methodological quality both of randomised and non-randomised studies of health care interventions. J Epidemiol Community Health 1998;52: 377-384.

16. Moher D, Liberati A, Tetzlaff J, Altman DG; RISMA Group. Preferred reporting items for systematic reviews and meta-analyses: the PRISMA statement. BMJ 2009; 339:b2535.

17. Hamazaki $Y$, Morikawa $Y$, Nakamura K, et al. The effects of sleep duration on the incidence of cardiovascular events among middle-aged male workers in Japan. Scand J Work Environ Health 2011;37:411-417.

18. Kakizaki M, Kuriyama S, Nakaya N, et al. Long sleep duration and cause-specific mortality according to physical function and self-rated health: the Ohsaki Cohort Study. J Sleep Res 2013;22:209-216.

19. Kronholm E, Laatikainen T, Peltonen M, Sippola R, Partonen T. Self-reported sleep duration, all-cause mortality, cardiovascular mortality and morbidity in Finland. Sleep Med 2011;12:215-221.

20. Van Den Berg JF, Van Rooij FJ, Vos H, et al. Disagreement between subjective and actigraphic measures of sleep duration in a population-based study of elderly persons. J Sleep Res 2008;17:295-302.

21. Lauderdale D, Knutson KL, Yan LL, Liu K, Rathouz PJ. Sleep duration: how well do self-reports reflect objective measures? The CARDIA Sleep Study. Epidemiology 2008; 19:838-845.

22. Shankar A, Koh WP, Yuan JM, Lee HP, Yu MC. Sleep duration, coronary heart disease mortality among Chinese adults in Singapore: a population-based cohort study. Am J Epidemiol 2008;168:1367-1373.

23. Meisinger C, Heier M, Löwel H, Schneider A, Döring A. Sleep duration and sleep complaints and risk of myocardial infarction in middle-aged men and women from the general population: the MONICA/KORA Augsburg cohort study. Sleep 2007;30:1121-1127.
24. Leng Y, Wainwright NW, Cappuccio FP, et al. Self-reported sleep patterns in a British population cohort. Sleep Med 2014;15:295-302.

25. Grandner MA, Hale L, Moore M, Patel NP. Mortality associated with short sleep duration: the evidence, the possible mechanisms, and the future. Sleep Med Rev 2010; 14:191-203.

26. Spiegel K, Leproult R, Van Cauter E. Impact of sleep debt on metabolic and endocrine function. Lancet 1999;354: $1435-1439$.

27. Meier-Ewert HK, Ridker PM, Rifai N, et al. Effect of sleep loss on C-reactive protein, an inflammatory marker of cardiovascular risk. J Am Coll Cardiol 2004;43:678-683.

28. Hademenos GJ, Massoud TF. Biophysical mechanisms of stroke. Stroke 1997;28:2067-2077.

29. Cappuccio FP, Miller MA. Sleep and mortality: cause, consequence, or symptom? Sleep Med 2013;14:587-588.

30. Patel SR, Zhu X, Storfer-Isser A, et al. Sleep duration and biomarkers of inflammation. Sleep 2009;32:200-204.

31. Grandner MA, Buxton OM, Jackson N, Sands-Lincoln M, Pandey A, Jean-Louis G. Extreme sleep durations and increased C-reactive protein: effects of sex and ethnoracial group. Sleep 2013;36:769-779E.

32. Abe T, Aoki T, Yata S, Okada M. Sleep duration is significantly associated with carotid artery atherosclerosis incidence in a Japanese population. Atherosclerosis 2011; 217:509-513.

33. Ramos AR, Dong C, Rundek T, et al. Sleep duration is associated with white matter hyperintensity volume in older adults: the Northern Manhattan Study. J Sleep Res 2014;23:524-530.

34. Ramos AR, Jin Z, Rundek T, et al. Relation between long sleep and left ventricular mass (from a multiethnic elderly cohort). Am J Cardiol 2013;112:599-603.

35. Khawaja O, Sarwar A, Albert CM, Gaziano JM, Djoussé L. Sleep duration and risk of atrial fibrillation (from the Physicians' Health Study). Am J Cardiol 2013;111:547-551.

36. Wolf PA, Dawber TR, Thomas HE Jr, Kannel WB. Epidemiologic assessment of chronic atrial fibrillation and risk of stroke: the Framingham Study. Neurology 1978;28: 973-977.

37. Wolff B, Völzke H, Schwahn C, Robinson D, Kessler C, John U. Relation of self-reported sleep duration with carotid intima-media thickness in a general population sample. Atherosclerosis 2008;196:727-732.

38. Youngstedt SD, Jean-Louis G, Bootzin RR, et al. Chronic moderate sleep restriction in older long sleepers and older average duration sleepers: a randomized controlled trial. Contemp Clin Trials 2013;36:175-186.

\section{Get Connected. Stay Connected.}

Connect with the American Academy of Neurology's popular social media channels to stay up-todate on the latest news and breakthroughs in neurology, and network with peers and neurology thought leaders. Visit AAN.com/Connect. 


\section{Neurology}

\section{Sleep duration and risk of fatal and nonfatal stroke: A prospective study and meta-analysis \\ Yue Leng, Francesco P. Cappuccio, Nick W.J. Wainwright, et al. Neurology 2015;84;1072-1079 Published Online before print February 25, 2015 DOI 10.1212/WNL.0000000000001371}

This information is current as of February 25, 2015

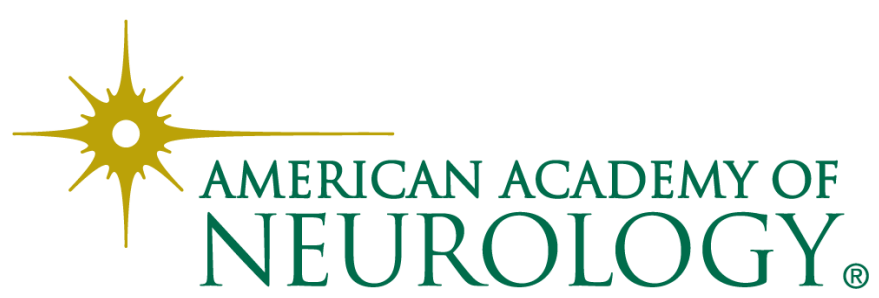




\section{Updated Information \& Services}

\section{Supplementary Material}

\section{References}

Citations

Subspecialty Collections

Permissions \& Licensing

Reprints including high resolution figures, can be found at: http://n.neurology.org/content/84/11/1072.full

Supplementary material can be found at: http://n.neurology.org/content/suppl/2015/02/25/WNL.0000000000001 371.DC1 http://n.neurology.org/content/suppl/2015/02/25/WNL.0000000000001 371.DC2

This article cites 38 articles, 10 of which you can access for free at: http://n.neurology.org/content/84/11/1072.full\#ref-list-1

This article has been cited by 4 HighWire-hosted articles: http://n.neurology.org/content/84/11/1072.full\#\#otherarticles

This article, along with others on similar topics, appears in the following collection(s):

\section{All Cerebrovascular disease/Stroke}

http://n.neurology.org/cgi/collection/all_cerebrovascular_disease_strok e

All epidemiology

http://n.neurology.org/cgi/collection/all_epidemiology

All Sleep Disorders

http://n.neurology.org/cgi/collection/all_sleep_disorders

Cohort studies

http://n.neurology.org/cgi/collection/cohort_studies

Incidence studies

http://n.neurology.org/cgi/collection/incidence_studies

Information about reproducing this article in parts (figures,tables) or in its entirety can be found online at:

http://www.neurology.org/about/about_the_journal\#permissions

Information about ordering reprints can be found online:

http://n.neurology.org/subscribers/advertise

Neurology ${ }^{\circledR}$ is the official journal of the American Academy of Neurology. Published continuously since 1951, it is now a weekly with 48 issues per year. Copyright @ 2015 American Academy of Neurology. All rights reserved. Print ISSN: 0028-3878. Online ISSN: 1526-632X.

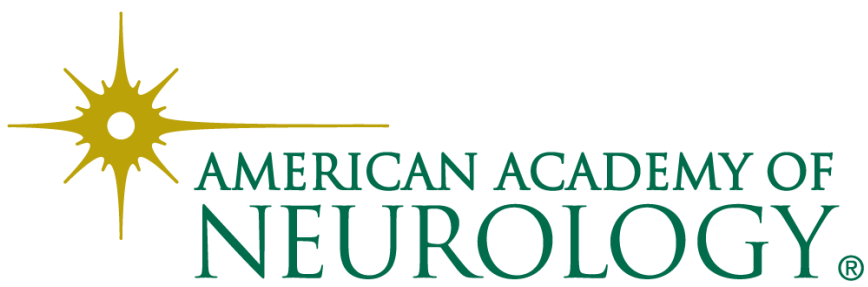

